\title{
Micro-Scale Variability of Air Temperature within a Local Climate Zone in Berlin, Germany, during Summer
}

\author{
Justus A. Quanz * (D), Susanne Ulrich, Daniel Fenner (D), Achim Holtmann \\ and Jonas Eimermacher \\ Chair of Climatology, Institute of Ecology, Technische Universität Berlin, Rothenburgstraße 12, \\ D-12165 Berlin, Germany; susanne.ulrich@campus.tu-berlin.de (S.U.); daniel.fenner@tu-berlin.de (D.F.); \\ achim.holtmann@tu-berlin.de (A.H.); jonas.eimermacher@campus.tu-berlin.de (J.E.) \\ * Correspondence: j.quanz@posteo.de; Tel.: +49-(0)30-31473195
}

Received: 19 December 2017; Accepted: 12 January 2018; Published: 17 January 2018

\begin{abstract}
The urban climate, especially the near-surface air temperature $(T)$, is influenced to large amounts by urban surface properties on the local-scale. Landscape classification schemes, like the Local Climate Zone (LCZ) concept, classify neighbourhoods on this scale based on their surface properties, neglecting sub-scale heterogeneity in the urban structure and its potential effects on $T$. To quantify sub-scale $T$ variability, a measurement campaign with eleven stationary $T$ sensors was conducted within one LCZ (class $2_{\mathrm{B}}$, compact midrise with scattered trees) in Berlin, Germany, during 22 days in summer 2016. Correlation analyses were performed between observed spatial $T$ differences and micro-scale morphometric parameters around the measurement sites, such as sky view factor and building surface fraction. The results show mean night-time $T$ differences of up to $1 \mathrm{~K}$ between the different sites. On a clear, calm and dry day, the daytime difference reached $3 \mathrm{~K}$. At night-time, the variability can be best explained by the building surface fraction within a radius of $50 \mathrm{~m}$. Further, a nocturnal cooling influence of a neighbouring green space could be observed. The observed micro-scale $T$ variability was smaller than $T$ differences to other LCZ classes, highlighting the applicability of the LCZ concept.
\end{abstract}

Keywords: urban climate; local climate zone (LCZ); microclimate; variability; air temperature; Berlin

\section{Introduction}

The Earth's surface influences the atmosphere through a variety of processes and on different spatial scales, leading to characteristic atmospheric phenomena. These range from synoptic weather conditions on the macro-scale $(>2000 \mathrm{~km})$, over mesoscale ( $>2 \mathrm{~km}$ up to $2000 \mathrm{~km})$ processes such as thunderstorms or land-sea breezes, down to micro-scale $(<1 \mathrm{~cm}$ up to $2 \mathrm{~km})$ features such as small-scale turbulence induced by individual roughness elements [1]. In an urban context, the air temperature $(T)$ of the near-ground atmosphere within the urban canopy layer (UCL), i.e., the atmospheric layer stretching from the ground to approximately the mean building height [2], is largely influenced by the surroundings within several hundred meters to a few kilometres. This scale can be referred to as the local-scale $[3,4]$.

The "Local Climate Zone" (LCZ) concept, a classification scheme for different types of land cover and land use, explicitly addresses this local-scale and assigns specific classes to areas of similar land surface characteristics [5]. It is designed to be globally applicable, to enable comparability between different urban climate studies and to overcome the vague differentiation of measurement sites as "rural" or "urban" in urban heat island (UHI) studies [5]. The concept is based on several land cover (e.g., building surface fraction, vegetation surface fraction), morphological (e.g., height of roughness 
elements, sky view factor) and anthropogenic (anthropogenic heat output) parameters. These are known to have an influence on the radiation balance, heat transport processes, the airflow, moisture availability and thus on near-surface $T$ [5]. Each LCZ class has a typical range of these parameters and the scheme differentiates between ten "built" or "urban" and seven "natural" classes. Further, subclasses as a combination of these 17 classes are possible. To account for the fact that there is a difference between comparing stations belonging to the same LCZ class but in different locations within an urban region and comparing stations within one specific neighbourhood of one LCZ class, we distinguish between the terms "LCZ class" as a category of land cover properties and "LCZ" describing a spatially continuous area belonging to one LCZ class.

A number of studies using the LCZ scheme could show that similar LCZs within a city also exhibit similar $T$ characteristics [6-8]. Moreover, Stewart et al. [9] showed that spatial $T$ differences $(\triangle T)$ between "urban" LCZ classes (e.g., LCZ 1 or 2) and "rural" ones (e.g., LCZ D) in different cities like Nagano, Japan, Vancouver, Canada and Uppsala, Sweden, are comparable. The $\Delta T$ between LCZ classes detected by further studies in various cities are also corresponding [7,10-12]. Moreover, the LCZ concept allows the characterization of inner-city differentiation of $T$, as shown by several studies $[8,10,13]$. Thus, the underlying assumption that surface structure and land cover on the local-scale essentially drive thermal differences within the UCL seems to be valid and thus the LCZ scheme to be applicable.

Despite the general finding that $\triangle T$ between LCZ classes are similar across cities, recent studies in Oloumouc, Czech Republic [14], Szeged, Hungary [8] and Berlin, Germany [15], detected intra-LCZ class $\Delta T$ of several $K$. Neighborhoods of the same LCZ class within the same city but located in different parts of the city, showed differences to one another that were sometimes as large as or even larger than $\triangle T$ between different LCZ classes. Such intra-LCZ class variability was especially strong at night-time and during summer months $[8,15]$. Similar findings were also made by Houet and Pigeon [16] for Toulouse, France, using the "Urban Climate Zone" concept, a predecessor of the LCZ scheme. Three reasons for such an intra-class $T$ variability can be identified. First, the $T$ regime of a LCZ within the city is influenced by surrounding areas through advection on the local scale (from neighbouring LCZs) and beyond (especially for large cities) $[8,17]$. Second, LCZs of the same class may differ in surface characteristics as LCZ classes allow a range of parameters. Third, surface parameters within a LCZ vary on the micro-scale and have an influence on $T$. Thus, $T$ measured at one point in the LCZ can differ from $T$ measured at another point in the same LCZ [14]. Underlying driving factors on the micro-scale are, e.g., land cover (e.g., building surface fraction), morphometric parameters (e.g., sky view factor), or urban design features (e.g., street orientation) [18-21].

A separation and quantification of the causes of intra-class $T$ variability is, however, only possible if distributed measurements are carried out within one neighbourhood in addition to measurements across different neighbourhoods of the same class. In fact, some studies indicate micro-scale $T$ variability within short distances, i.e., $\Delta T$ within a specific neighborhood $[7,9]$. Such studies typically use data from mobile measurements, though some examples of micro-scale networks with stationary measurements (at least for a limited amount of time) exist for urban [22,23] and rural environments [24,25]. They show micro-scale $\Delta T$ that are of the same magnitude as inter-LCZ class $\Delta T$ found in the literature. Micro-scale $T$ variability has therefore important implications, e.g., for the selection of a "rural" reference site [24] or a representative measurement location for a specific LCZ [14]. It is thus important to quantify such intra-LCZ $\Delta T$ and to understand the driving factors to allow for a sound interpretation of $\Delta T$ between LCZ classes.

The present study aims at adding insights into this subject by focusing on one neighbourhood of a specific LCZ class, using stationary measurements during a measurement campaign in summer 2016. The campaign was carried out in a built-up urban neighbourhood in Berlin, Germany, of LCZ $2_{\mathrm{B}}$ (compact midrise with scattered trees). The structure and morphological characteristics of the investigated neighbourhood are typical for Berlin's city centre and many other European cities. Besides, the investigated neighbourhood is adjacent to a former airport that is now an inner-city green 
space of LCZ D (low plants). This allows to investigate the influence of such a "natural" LCZ onto the $T$ characteristics of an adjacent "urban" LCZ. Specifically, the following questions are addressed:

(1) How large is the intra-LCZ T variability within one LCZ and can it be explained by micro-scale characteristics around the measurement sites?

(2) What influence does the adjacent urban green space as a distinctly different LCZ have onto the $T$ regime within the study area?

(3) How do the intra-LCZ $\Delta T$ within the study area compare to $\Delta T$ between different LCZ classes within Berlin?

\section{Materials and Methods}

\subsection{Study Area and Local Climate Zone Classification}

The city of Berlin, with a population of about 3.65 Mio inhabitants in 2016 [26], is situated in north-eastern Germany $\left(52.52^{\circ} \mathrm{N}, 13.40^{\circ} \mathrm{E}\right)$. The conurbation covers an area of about $892 \mathrm{~km}^{2}$, with a maximum extension of $45 \mathrm{~km}$ in east-west and $38 \mathrm{~km}$ in north-south direction. The topography is mainly flat, stretching from an ice age glacial valley with the river Spree at about $30 \mathrm{~m}$ above mean sea level (amsl) to the Barnim Plateau in the north and the Teltow Plateau in the south at about $70 \mathrm{~m}$ amsl with only small, solitary elevations of up to $120 \mathrm{~m}$ amsl [27].

According to Köppen's climate classification the city has a maritime temperate climate (Cfb) [28] with an annual average $T$ of $9.9^{\circ} \mathrm{C}$ and a mean annual precipitation of $576 \mathrm{~mm}(1981-2010)$ at the centrally located site Berlin-Tempelhof (TEMP), maintained by the German Weather Service (DWD). Precipitation falls relatively even throughout the year with summer being the season with typically more rainfall than during the other seasons [29].

The study area Schillerkiez is a centrally located residential area in the district Neukölln, south-east of the inner city $\left(52.475^{\circ} \mathrm{N}, 13.422^{\circ} \mathrm{E}\right)$ with a size of approximately $0.43 \mathrm{~km}^{2}$ at $53 \mathrm{~m}$ amsl [27]. To the west, it flanks the former airport Tempelhofer Feld (THF), today's largest urban green space $\left(3 \mathrm{~km}^{2}\right)$ in Berlin. The border of the THF, which lies $4 \mathrm{~m}$ below the Schillerkiez, is characterized by a line of bushes and trees. The north-west of the study area borders the park area Hasenheide on a slight downward slope. Smaller green spaces adjoin the area to the south and south-east. The neighbouring developed area to the east is similarly constructed as the study area but also located on a slight downward slope (Figure 1).

The Schillerkiez is characterized by an up to five-story perimeter block development and numerous roadside trees (mostly Tilia). Geometric and surface properties of the area relevant for a classification of the LCZ were calculated from building and vegetation digital surface models of the Schillerkiez at $1 \mathrm{~m}$ resolution [30]. The datasets were used to calculate the areal sky view factor $\left(\mathrm{SVF}_{\text {area }}\right)$ resulting from buildings and vegetation, using the software SOLWEIG 2015a [31]. The trunk zone of the vegetation was set to a fraction of 0.25 of the vegetation height and a transmissivity of the vegetation canopy of 0.08 was assumed, according to Konarska et al. [32]. SVF area values were calculated at ground level, excluding grid cells with buildings.

The same datasets were used to calculate the vegetation surface fraction $\left(f_{V}\right)$, the building surface fraction $\left(\mathrm{f}_{\mathrm{B}}\right)$ and the average building height. The vegetation cover was set as pervious surface. Areas with no vegetation cover and no buildings were defined as impervious surfaces. Note that "impervious surfaces" include bare soil, since the two types of surfaces could not be distinguished due to lack of data. No water surfaces are present in the study area. The aspect ratio (AR), i.e., the ratio of the building height to the street width, was calculated by measuring the building height and street width at three spots in every street. The mean AR of each street was then multiplied by the relative street length to calculate the weighted mean AR for the entire study area. This weighted mean AR for the Schillerkiez is 0.94. All other calculated parameters are presented in Table 1. 


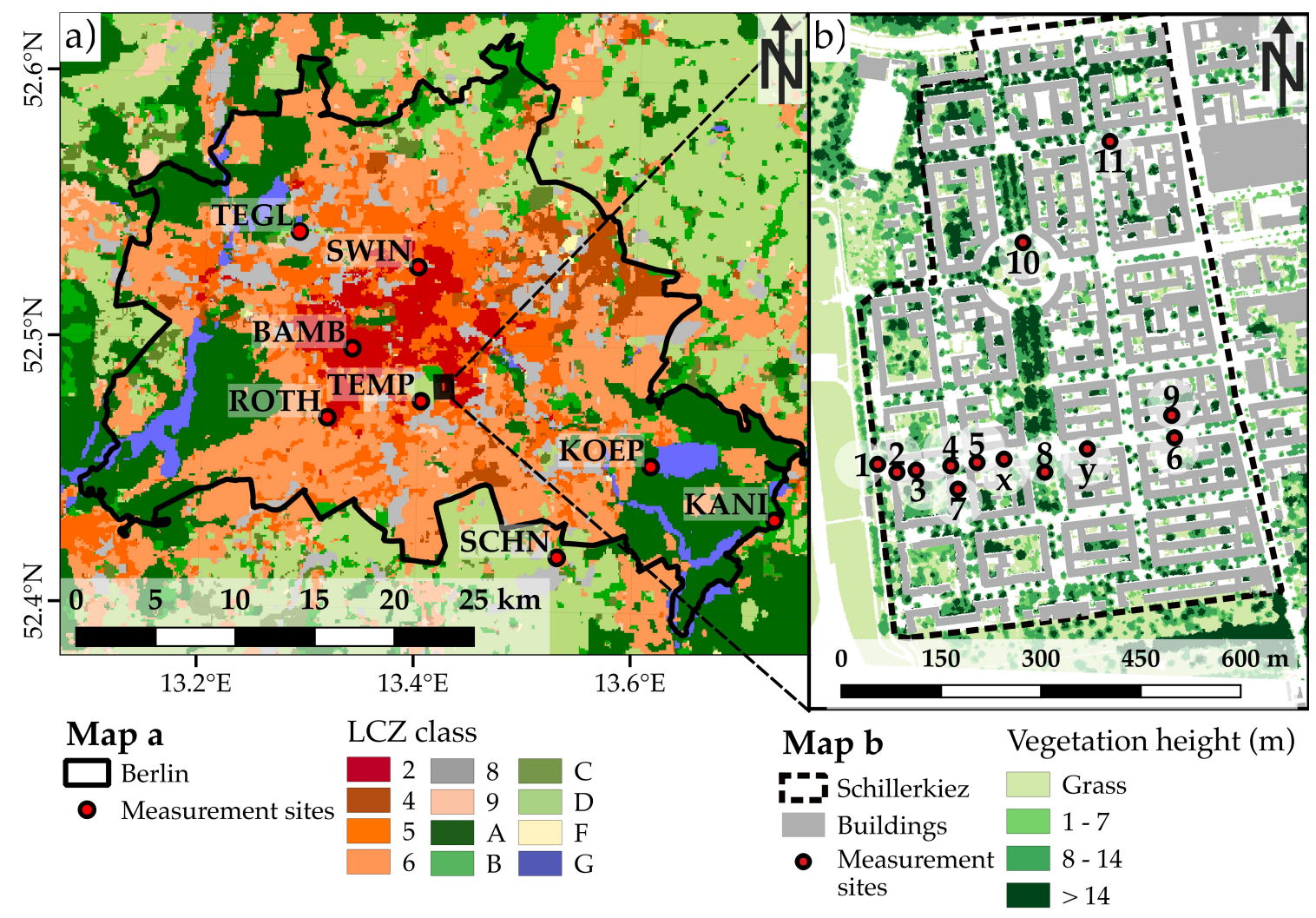

Figure 1. (a) Local climate zone (LCZ) classes in and around Berlin according to Fenner et al. [15], location of study area (black rectangle) and location of measurement sites. (b) Study area Schillerkiez, displayed as buildings and vegetation height [30] and measurement sites during the measurement campaign in summer 2016.

According to the parameter values for each LCZ class as given by Stewart and Oke [5], the Schillerkiez can best be classified as LCZ $2_{\mathrm{B}}$ (compact midrise with scattered trees). The fact that the $\mathrm{SVF}_{\text {area }}$ in the study area is slightly smaller than the defined values for a "pure" LCZ 2 can be explained by the high number of street trees in the Schillerkiez and hence the sub-classification LCZ $2 \mathrm{~B}$ was chosen. The slightly higher pervious surface fraction compared to the values given in Stewart and Oke [5] can also be caused by the numerous trees. However, it should be noted that the pervious surface fraction including tree crowns might be overestimated as the tree crowns are typically larger than the tree pit on the ground.

In order to address the question how the intra-LCZ $T$ within the study area compares to $T$ of other LCZs in Berlin, $T$ data during the measurement campaign from four measurement sites of the Urban Climate Observation Network (UCON) [11], operated by the Chair of Climatology at the Technische Universität Berlin and three sites operated by the DWD were used (Figure 1a, Table 1). The sites were selected since they represent the most prevalent LCZ classes in Berlin [15] — both inside and outside of the built-up city structure-i.e., site BAMB (LCZ 2, compact midrise), SWIN (LCZ 5, open midrise), ROTH (LCZ 6, open low-rise), KOEP (LCZ A, dense trees), KANI (LCZ B, scattered trees), SCHN and TEMP (both LCZ D, low plants). The surface parameters relevant for a LCZ classification of these sites were calculated as described above for a $250 \mathrm{~m}$ radius around each site (Table 1). The LCZ-classification of SCHN is based on local expert knowledge and aerial photographs, since the needed data were not available for this site. Data from UCON sites were adjusted by gain and offset values to a reference sensor, quality-checked and aggregated to hourly averages as described by Meier et al. [33], DWD data are quality-checked products at one-hourly resolution [29,34]. 
Table 1. Meta data for the study area Schillerkiez and measurement sites in other Local Climate Zones (LCZs). Land cover characteristics are given as spatial mean values for a $250 \mathrm{~m}$ radius around each site or for the complete area (Schillerkiez). The LCZ classification of SCHN is based on local expert knowledge and aerial photographs. UCON: Urban Climate Observation Network by Technische Universität Berlin, DWD: German Weather Service (Deutscher Wetterdienst), SVF area: areal mean sky view factor. (@ all aerial photographs [35], except SCHN (@ [36]). The circle in the aerial photograph of the Schillerkiez serves for size comparison.

\begin{tabular}{|c|c|c|c|c|}
\hline Site (Operator) & Schillerkiez & $\begin{array}{l}\text { BAMB (UCON) Bamberger } \\
\text { Straße }\end{array}$ & $\begin{array}{c}\text { KANI (DWD) } \\
\text { Berlin-Kaniswall }\end{array}$ & KOEP (UCON) Köpenick \\
\hline Latitude, Longitude $\left({ }^{\circ}\right)$ & $52.475 \mathrm{~N}, 13.422 \mathrm{E}$ & $52.4964 \mathrm{~N}, 13.3375 \mathrm{E}$ & $52.4040 \mathrm{~N}, 13.7309 \mathrm{E}$ & $52.4330 \mathrm{~N}, 13.6157 \mathrm{E}$ \\
\hline Elevation (m amsl) & 53 & 36 & 33 & 36 \\
\hline $\begin{array}{l}\text { Building/Pervious/Impervious and } \\
\text { bare soil surface fraction (-) }\end{array}$ & $0.40 / 0.26 / 0.34$ & $0.34 / 0.33 / 0.32$ & $0.01 / 0.37 / 0.56$ & $0.00 / 0.99 / 0.01$ \\
\hline Mean building/Vegetation height (m) & $19.4 / 10.2$ & $20.8 / 9.5$ & $3.4 / 7.2$ & $-/ 14.4$ \\
\hline $\mathrm{SVF}_{\text {area }}(-)$ & 0.21 & 0.24 & 0.9 & 0.06 \\
\hline LCZ class & $2_{B}-$ compact mid-rise with scattered trees & $\begin{array}{l}2_{\mathrm{B}} \text { - compact mid-rise with } \\
\text { scattered trees }\end{array}$ & B-scattered trees & A-dense trees \\
\hline Aerial view (250 m radius) & 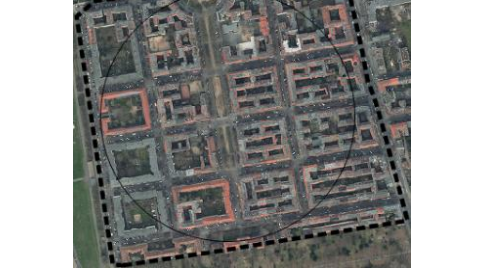 & (1) & & - \\
\hline Sensor (all with white radiation shields) & $\begin{array}{l}\text { Driesen + Kern GmbH DK390-DM-4M } \\
\text { HandyLog (11 sensors, c.f. Figure 1b), } \\
\text { passive ventilation }\end{array}$ & $\begin{array}{l}\text { Campbell CS215, active } \\
\text { ventilation during sunlit } \\
\text { periods }\end{array}$ & $\begin{array}{l}\text { Eigenbrodt LTS2000, active } \\
\text { ventilation }\end{array}$ & $\begin{array}{c}\text { Campbell CS215, active ventilation } \\
\text { during sunlit periods }\end{array}$ \\
\hline Height (m agl) & 3 & 2.5 & 2 & 2 \\
\hline Comment & & Sensor attached to balcony & & Sensor below tree canopy \\
\hline
\end{tabular}


Table 1. Cont.

\begin{tabular}{|c|c|c|c|c|}
\hline Site (Operator) & ROTH (UCON) Rothenburgstraße & $\begin{array}{l}\text { SCHN (DWD) } \\
\text { Berlin-Schönefeld }\end{array}$ & $\begin{array}{c}\text { SWIN (UCON) } \\
\text { Swinemünder Straße }\end{array}$ & $\begin{array}{c}\text { TEMP (DWD) } \\
\text { Berlin-Tempelhof }\end{array}$ \\
\hline Latitude, Longitude $\left(^{\circ}\right)$ & $52.4572 \mathrm{~N}, 13.3158 \mathrm{E}$ & $52.3807 \mathrm{~N}, 13.5306 \mathrm{E}$ & $52.5431 \mathrm{~N}, 13.3969 \mathrm{E}$ & $52.4675 \mathrm{~N}, 13.4021 \mathrm{E}$ \\
\hline Elevation (m amsl) & 47 & 46 & 47 & 48 \\
\hline $\begin{array}{l}\text { Building/Pervious/Impervious and } \\
\text { bare soil surface fraction (-) }\end{array}$ & $0.19 / 0.61 / 0.19$ & $-/-/-$ & $0.24 / 0.40 / 0.35$ & $0.1 / 81.2 / 18.7$ \\
\hline Building/Vegetation height $(\mathrm{m})$ & $12.4 / 9.9$ & $-/-$ & $16.4 / 6.9$ & $3.0 / 0.2$ \\
\hline $\mathrm{SVF}_{\text {area }}(-)$ & 0.23 & - & 0.34 & 0.96 \\
\hline LCZ class & 62014open low-rise & D-low plants & 5-open midrise & D—low plants \\
\hline \multicolumn{5}{|l|}{ Aerial view ( $250 \mathrm{~m}$ radius) } \\
\hline Sensor (all with white radiation shields) & $\begin{array}{l}\text { Campbell CS215, active ventilation during } \\
\text { sunlit periods }\end{array}$ & $\begin{array}{c}\text { Eigenbrodt LTS2000, active } \\
\text { ventilation }\end{array}$ & $\begin{array}{l}\text { Campbell CS215, active ventilation } \\
\text { during sunlit periods }\end{array}$ & $\begin{array}{c}\text { Eigenbrodt LTS2000, active } \\
\text { ventilation }\end{array}$ \\
\hline Height (m agl) & 2 & 2 & 2 & 2 \\
\hline Comment & & $\begin{array}{l}\text { Airport station, located on } \\
\text { grassland }\end{array}$ & & \\
\hline
\end{tabular}




\subsection{Measurement Campaign}

The measurement campaign was conducted with stationary measurements at eleven locations within the Schillerkiez (Figure 1b) for a period of 22 days from 15 June 2016 to 07 July 2016. The weather conditions during the measurement period are depicted in Figure 2. There was considerable variation during the period with cool and rainy days in the beginning and several hot and dry days in the middle. Over the whole period westerly winds dominated, showing also the highest wind speeds.

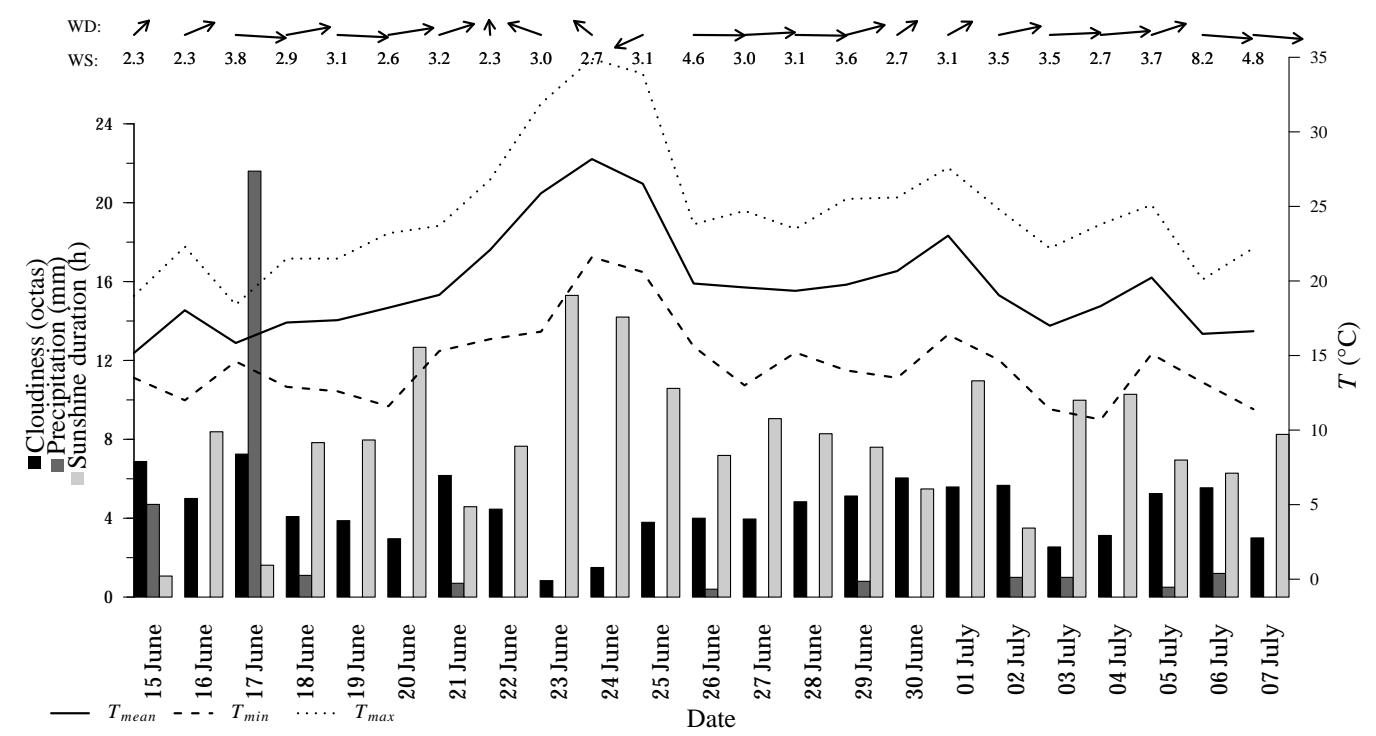

Figure 2. Weather conditions during the measurement campaign in summer 2016 at Berlin-Tempelhof, (TEMP) (German Weather Service, DWD). Cloudiness data are from TEGL (Berlin-Tegel). WD: wind direction, WS: wind speed, $T$ : air temperature, $T_{\text {mean }}$ : daily mean $T, T_{\min }:$ daily minimum $T, T_{\max }$ : daily maximum $T$.

At each of the eleven measurement sites $T$ was measured at 1-min resolution (instantaneous values) with Driesen+Kern GmbH DK390-DM-4M HandyLog sensors (resolution of $0.01 \mathrm{~K}$, specified device error of $\leq 0.5 \mathrm{~K}$ between $0{ }^{\circ} \mathrm{C}$ and $40{ }^{\circ} \mathrm{C}$ ). The sensors were mounted in white passively ventilated radiation screens and fixed to tree trunks in $3 \mathrm{~m}$ above ground level (agl). The higher sensor height compared to the standard height of $2 \mathrm{~m}$ agl was chosen to avoid vandalism and as suggested by Oke [37] for $T$ measurements in street canyons. All sensors were attached to the north side of the tree trunks. In W-E-streets, all trees used for attaching the sensors were located on the south side of the street.

The measurement sites were, on the one hand, selected to cover different and characteristic features within the study area, i.e., street canyons (W-E direction: sites 1 to 6, 11; N-S direction: site 7), open squares (site 10), small parks or park-like boulevards (site 8) and courtyards (site 9). On the other hand, the locations were chosen to address the question if the THF has an effect on $T$ in the study area. Thus, sensors 1 to 6 were placed along an east-western street with distances between sensors increasing with distance to the THF. Two additional sensors in this street (sensors $x$ and $y$, Figure 1b) were lost during the measurement campaign.

For all measurement sites different average urban morphometric parameters $\left(f_{B}, f_{V}, S V F_{\text {area }}\right)$ for radii of $10 \mathrm{~m}$ to $100 \mathrm{~m}$ were calculated. In the following analyses, the parameters of the $50 \mathrm{~m}$ radius were used since these show the best correlations with $T$ (see Appendix A).

Beside the $\mathrm{SVF}_{\text {area, }}$ a $\mathrm{SVF}_{\text {photo }}$ was calculated for each measurement site from fish-eye photographs, using the software SOLWEIG 2015a 1D [31]. The photos were taken at $1 \mathrm{~m}$ height in the middle of the street (except for the courtyard) next to the respective tree with Canon (Tokyo, Japan) EOS 700D with Sigma (Asao-ku, Japan) 4.5 mm F2.8 EX DC HSM fish-eye lens ( $180^{\circ}$ angle). 
Positioning the camera in the middle of the street instead of right beside the tree trunk was done because taking the photograph directly under the tree crown would let the form of the tree crown, which we do not consider the relevant form factor determining $T$, dominate the resulting $S \mathrm{SF}_{\text {photo }}$. For each site, these urban morphometric parameters, the street orientation and the distance to the THF are shown in Table 2.

\subsection{Data Processing}

Except for one data logger, all data were collected at the end of the measurement campaign. The logger situated at site 9 had a lower data storage, thus the data had to be read once during the measurement period. To avoid distorted values in the data set, values measured during the reading process were removed.

To identify unrealistic values, the absolute maximum $\left(37.3^{\circ} \mathrm{C}\right)$ and minimum $\left(3.0^{\circ} \mathrm{C}\right) \mathrm{T}$ during June and July measured at TEMP in the past 30 years (1986-2015) were used and a buffer of $\pm 3 \mathrm{~K}$ added to these values. All measurement data were within the calculated range.

The data of each sensor were then adjusted by gain and offset values that were calculated from comparative measurements conducted in a climate chamber (temperature range: $0-30{ }^{\circ} \mathrm{C}$, seven temperature levels at $5 \mathrm{~K}$ steps). A reference sensor (Vaisala HMP155, accuracy: $\pm 0.28 \mathrm{~K}$ in range $0-40^{\circ} \mathrm{C}$ ) was used to obtain the gain and offset values of each sensor through linear regression, using the same methodology as with UCON data, described in Meier et al. [33]. All UCON and DWD data were adjusted to the reference height of the Schillerkiez ( $53 \mathrm{~m}$ amsl) using the dry adiabatic lapse rate $\left(-9.8 \times 10^{-3} \mathrm{~K} \cdot \mathrm{m}^{-1}\right)$.

Night-time (12:00 a.m.-2:59 a.m. UTC + 1) and daytime (12:00 p.m.-2:59 p.m. UTC + 1) periods were analysed separately. The night-time period covers the last three full hours before sunrise, as by then ( $3-5 \mathrm{~h}$ after sunset) local-scale $\Delta T$ are well developed and a pronounced influence from micro-scale conditions can also be expected [6,38,39]. As daytime period, the same timespan shifted by twelve hours was chosen. By then, daily maximum $T$ typically occurs in Berlin in summer. The $T$ values of these hours were aggregated to mean night- and daytime $T$ for each of the 22 days of the measurement campaign. The UCON and DWD data were also aggregated to these mean night- and daytime values.

In the following sections, the $T$ data at each site $\left(T_{i}\right)$ are presented as the deviation from the spatial mean $T$ of all $n$ sites in the Schillerkiez $\left(T_{S K}\right)$, where $n$ is the number of all sites in the Schillerkiez (11) and $j$ is any site in the Schillerkiez, i.e.,

$$
\Delta T_{S K}=T_{i}-T_{S K}=T_{i}-\left(\frac{1}{n} \sum_{j=1}^{n} T_{j}\right)
$$

or as the deviation from $T$ measured at TEMP $\left(T_{T E M P}\right)$, i.e.,

$$
\Delta T_{T E M P}=T_{i}-T_{T E M P}
$$

The temporal mean, i.e., $T$ or $\Delta T$ averaged over more than one night or day, is abbreviated with an overbar, e.g., $\overline{\Delta T_{S K}}$. Sites within the Schillerkiez where positive or negative $\Delta T_{S K}$ occur are referred to as hot- and cold spots, respectively.

Beside the mean conditions during the whole period, it was additionally investigated if $\Delta T_{S K}$ is more pronounced during clear, calm and dry weather conditions as reported for micro- and local-scale $\Delta T$ in Berlin and other cities $[5,6,10,15,40]$. For that part of the analysis, night-time data were restricted to clear (mean cloud cover $\leq 3$ octas), calm (mean wind speed $\leq 3 \mathrm{~m} / \mathrm{s}$ ) and dry (no precipitation) nights following 24 dry hours (total precipitation $\leq 0.1 \mathrm{~mm}$ ), resulting in ten nights. Wind speed, wind direction and precipitation data were obtained from TEMP. The data on cloud cover are from the weather station Berlin-Tegel (TEGL, DWD), since these data are not available at TEMP. A similar filter was used for the daytime data (mean wind speed $\leq 3 \mathrm{~m} / \mathrm{s}$, no precipitation, mean cloud cover $\leq 3$ octas). Here, only one day (24 June 2016) met the requirements. 
Table 2. Parameters describing the measurement sites in the study area Schillerkiez. Building surface fraction $\left(f_{B}\right)$, vegetation surface fraction $\left(f_{V}\right)$ and areal sky view factor $\left(\mathrm{SVF}_{\text {area }}\right)$ are given as spatial means for a $50 \mathrm{~m}$ radius around each site. $\mathrm{SVF}_{\text {photo }}$ : sky view factor derived from fish-eye photographs. THF: former airport Berlin-Tempelhof.

\begin{tabular}{|c|c|c|c|c|c|c|c|}
\hline Site & Latitude, Longitude $\left({ }^{\circ}\right)$ & $\mathrm{f}_{\mathrm{B}} / \mathrm{f}_{\mathrm{V}}(-)$ & $\mathrm{SVF}_{\text {area }} / \mathrm{SVF}_{\text {photo }}(-)$ & Fish-Eye Photograph & Street Orientation & Distance to Border of THF (m) & Site Photograph \\
\hline 1 & $52.47439 \mathrm{~N}, 13.41918 \mathrm{E}$ & $0.14 / 0.57$ & $0.48 / 0.44$ & & N-S & 13 & \\
\hline 2 & $52.47430 \mathrm{~N}, 13.41961 \mathrm{E}$ & $0.25 / 0.50$ & $0.29 / 0.37$ & & W-E & 40 & \\
\hline 3 & $52.47434 \mathrm{~N}, 13.42004 \mathrm{E}$ & $0.31 / 0.45$ & $0.24 / 0.30$ & & W-E & 70 & \\
\hline 4 & $52.47442 \mathrm{~N}, 13.42080 \mathrm{E}$ & $0.36 / 0.31$ & $0.23 / 0.42$ & & W-E & 122 & \\
\hline 5 & $52.47449 \mathrm{~N}, 13.42137 \mathrm{E}$ & $0.43 / 0.20$ & $0.24 / 0.32$ & & W-E & 162 & \\
\hline
\end{tabular}


Table 2. Cont.

\begin{tabular}{|c|c|c|c|c|c|c|c|}
\hline Site & Latitude, Longitude $\left(^{\circ}\right)$ & $\mathrm{f}_{\mathrm{B}} / \mathrm{f}_{\mathrm{V}}(-)$ & $\mathrm{SVF}_{\text {area }} / \mathrm{SVF}_{\text {photo }}(-)$ & Fish-Eye Photograph & Street Orientation & Distance to Border of THF (m) & Site Photograph \\
\hline 6 & $52.47497 \mathrm{~N}, 13.42570 \mathrm{E}$ & $0.47 / 0.15$ & $0.24 / 0.36$ & & W-E & 488 & \\
\hline 7 & $52.47412 \mathrm{~N}, 13.42098 \mathrm{E}$ & $0.36 / 0.39$ & $0.22 / 0.11$ & & N-S & 153 & \\
\hline 8 & $52.47441 \mathrm{~N}, 13.42288 \mathrm{E}$ & $0.24 / 0.48$ & $0.24 / 0.19$ & & N-S & 259 & \\
\hline 9 & $52.47519 \mathrm{~N}, 13.42571 \mathrm{E}$ & $0.53 / 0.19$ & $0.17 / 0.048$ & & courtyard & 452 & \\
\hline 10 & $52.47749 \mathrm{~N}, 13.42211 \mathrm{E}$ & $0.25 / 0.44$ & $0.27 / 0.41$ & & roundabout & 271 & \\
\hline 11 & $52.47893 \mathrm{~N}, 13.42387 \mathrm{E}$ & $0.46 / 0.27$ & $0.13 / 0.16$ & & W-E & 434 & \\
\hline
\end{tabular}


To further detect a possible influence on $T$ by the adjacent green space (THF), the relation between $T$ in the Schillerkiez and the distance to the eastern THF border for west wind and east wind situations was investigated. For this analysis, the data were stratified to nights with east wind $\left(45^{\circ}-135^{\circ}\right)$ and nights with west wind $\left(225^{\circ}-315^{\circ}\right)$ with maximum mean wind speed $\leq 3 \mathrm{~m} / \mathrm{s}$, resulting in three nights each. A similar investigation for daytime was not possible since no days of the measurement campaign met these requirements.

\section{Results}

\subsection{Air Temperature Variability within the Schillerkiez}

The $T$ variability within the Schillerkiez during day- and night-time is depicted in Figure 3, showing $\Delta T_{S K}$ for each site. At night-time, the difference between highest and lowest $\overline{\Delta T_{S K}}$ is about $1 \mathrm{~K}$, during the day this difference is smaller (about $0.5 \mathrm{~K}$ ). Maximum $\Delta T_{S K}$ detected are $2.1 \mathrm{~K}$ during night-time (30 June) and $2.9 \mathrm{~K}$ during daytime (24 June), both times between sites 1 and 9 . At night, site 1 , which is located directly at the border to the THF, is the coldest spot with only negative $\Delta T_{S K}$. In contrast, $\Delta T_{S K}$ at sites 9 and 6 , located in a courtyard and the street in front of it, are always positive. These two sites and sites 7 and 11 show a positive $\overline{\Delta T_{S K}}$ and can thus be identified as night-time hotspots. The results obtained for nights with clear, calm and dry conditions differ only slightly from conditions during all nights (Supplementary Material).

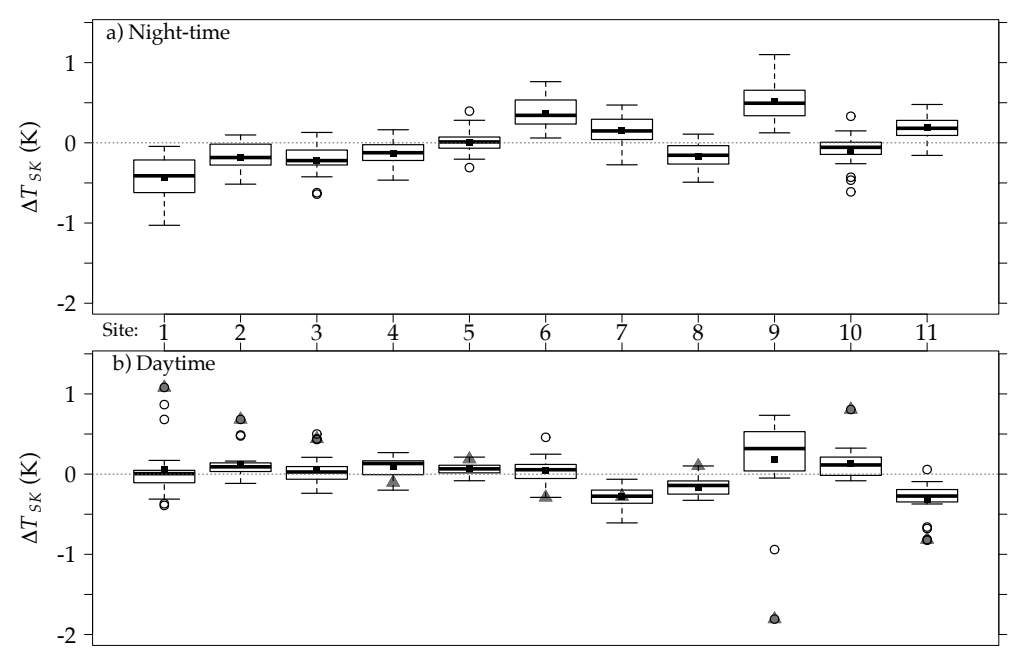

Figure 3. Air temperature $(T)$ difference in the study area Schillerkiez at the different measurement sites, depicted as the deviation $\left(\Delta T_{S K}\right)$ from the spatial mean $T$ for 22 nights and 22 days. Grey triangles mark the values during the clear, calm and dry day (24 June 2016). The bold black line in each box shows the temporal median, the black square the arithmetic mean $\left(\overline{\Delta T_{S K}}\right)$. Boxes include data points that are between the 1st and the 3rd quartile (interquartile range IQR). The whiskers show the remaining data points, maximum length is 1.5 times the IQR below the 1st and above the 3rd quartile. Data points outside of this are depicted as circles.

Regarding $T$ at daytime for all days, the differences between single sites are smaller than during night-time (Figure 3, lower panel). While site 9 is also usually the hottest spot at day, site 7 (N-S street) and 11 (E-W street in the north of the study area), which were identified as hotspots for night-time, show to be daytime cold spots. At daytime, more values exceed the range between median \pm 1.5 interquartile range than during the night (Figure 3). At six locations, these extreme values can be assigned to the clear, calm and dry day (grey triangles in Figure 3, lower panel). For this special day, 
the hot- and cold spots are inverted in comparison to the nocturnal situation, changing the courtyard (9) to a cold spot and site 1 close to THF to a hotspot.

\subsection{Influence of Neighbouring Green Space (LCZ D)}

When separating the data into nights with light east and west wind, nights with west wind show a $\overline{\Delta T_{T E M P}}$ range of about $1.5 \mathrm{~K}$ (Figure 4 , empty circles). Furthermore, $\overline{\Delta T_{T E M P}}$ is lower during these nights throughout the Schillerkiez, with the site closest to the THF (1) being about $0.5 \mathrm{~K}$ colder than TEMP located on the THF and the courtyard (9) more than $1 \mathrm{~K}$ warmer than TEMP. Further, $\overline{\Delta T_{T E M P}}$ increases with increasing distance to the THF border, showing a strong and highly significant positive correlation with the distance to the THF border (Figure 4).

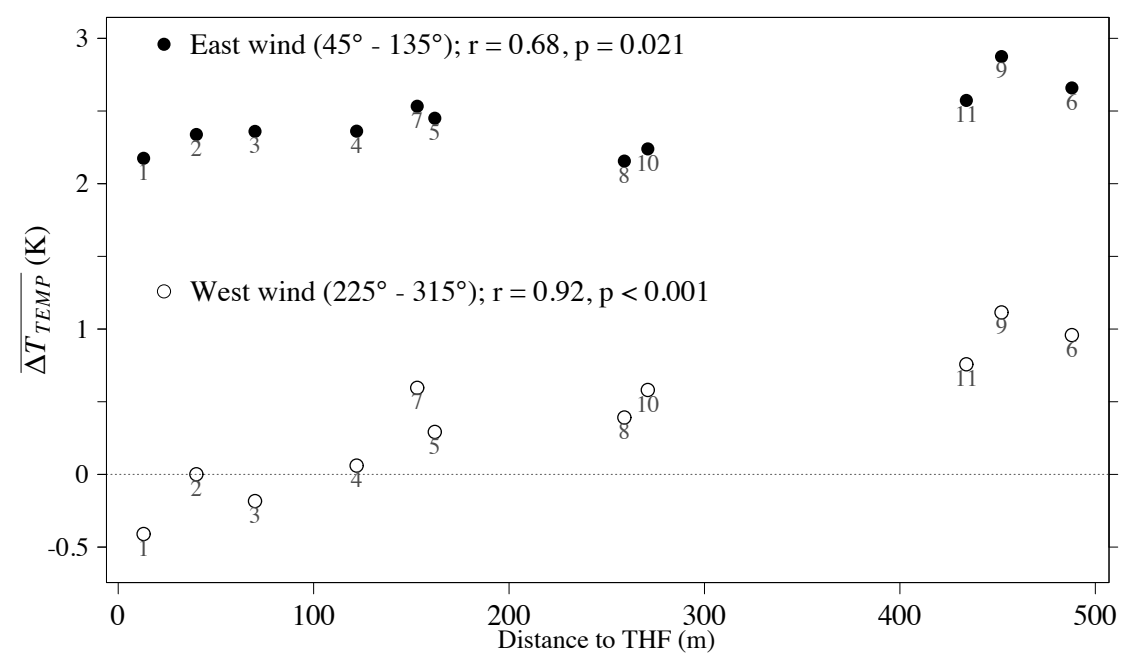

Figure 4. Mean night-time air temperature $(\bar{T})$ difference at each measurement site within the Schillerkiez in relation to the distance of each site to the eastern border of the Tempelhofer Feld (THF), depicted as the difference of individual $\bar{T}$ to $\bar{T}$ measured at the DWD station on the THF $\left(\overline{\triangle T_{T E M P}}, 1.4 \mathrm{~km}\right.$ west of the eastern THF border). Empty circles: conditions with light $(\leq 3 \mathrm{~m} / \mathrm{s})$ west wind (28 June, 3, 4 July); filled circles: conditions with light east wind (23, 25, 29 June).

For nights with east wind, the $\overline{\triangle T_{T E M P}}$ range is only about $0.8 \mathrm{~K}$ but all sites are distinctly warmer than TEMP (Figure 4, filled circles). $\overline{\Delta T_{T E M P}}$ is between $2.2 \mathrm{~K}$ at the border to the THF (1) and the park-like boulevard (8) and almost $3 \mathrm{~K}$ in the courtyard (9). The correlation of $\overline{\triangle T_{T E M P}}$ with the distance to the THF for nights with east wind is weaker and less significant (Figure 4).

\subsection{Correlation between $T$ and Micro-Scale Morphometric Parameters}

Figure 5 shows the correlations of the nocturnal $\overline{\Delta T_{S K}}$ with several micro-scale morphometric parameters. To isolate an influence of these parameters from an influence of the THF, only the nights with light east wind are investigated. During these nights, $\mathrm{f}_{\mathrm{B}}$ correlates strongly and positively with $\overline{\Delta T_{S K}}$ (Figure $5 \mathrm{c}, \mathrm{r}=0.91, p<0.001$ ). Contrary to that, the correlations of $\overline{\Delta T_{S K}}$ with $\mathrm{f}_{\mathrm{V}}$ and with the SVFs are negative. The correlation between $\overline{\Delta T_{S K}}$ and $f_{V}$ is strong and highly significant (Figure $5 \mathrm{~d}$ ), whereas the correlations with $\mathrm{SVF}_{\text {photo }}$ and $\mathrm{SVF}_{\text {area }}$ are weaker (Figure $5 \mathrm{a}, \mathrm{b}$ ).

During daytime, none of the investigated urban morphometric parameters shows significant correlations with the observed $\overline{\Delta T_{S K}}$ when considering all weather situations (Supplementary Material). However, when looking only at the day with clear, calm and dry conditions, reversed correlations for all parameters compared to the night-time situation are found (Figure 6). The correlation with $\mathrm{f}_{\mathrm{B}}$ is now negative and again the strongest $(\mathrm{r}=-0.86, p<0.001)$. 

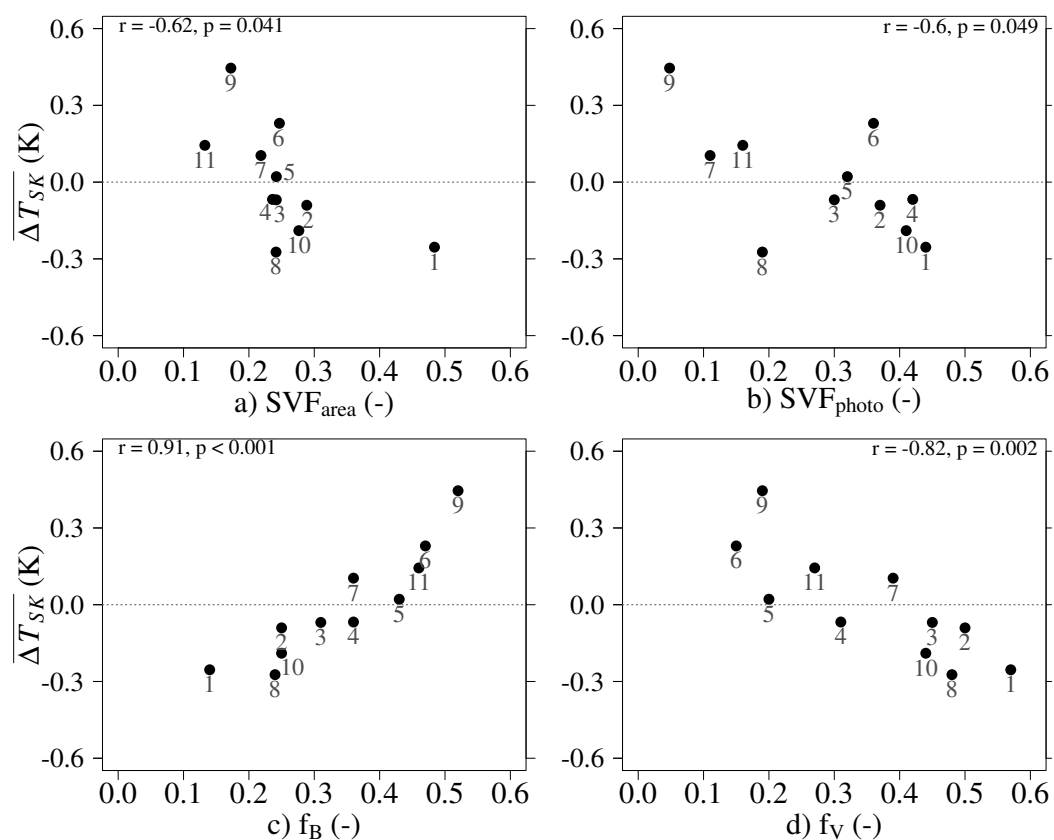

Figure 5. Night-time difference of each individual mean air temperature $(\bar{T})$ to the spatial mean night-time $\bar{T}$ of all sites $\left(\overline{\Delta T_{S K}}\right)$ at each measurement site within the Schillerkiez in relation to different urban morphometric parameters (a-d) during three nights in summer 2016 with light $(\leq 3 \mathrm{~m} / \mathrm{s})$ east wind (23, 25, 29 June). Correlation coefficients (r) and corresponding $p$-values are given for each parameter. $\mathrm{SVF}_{\text {area }}$ : areal sky view factor, $\mathrm{SVF}_{\text {photo }}$ : sky view factor calculated from fish-eye photos, $\mathrm{f}_{\mathrm{B}}$ : building surface fraction, $\mathrm{f}_{\mathrm{V}}$ : vegetation surface fraction.
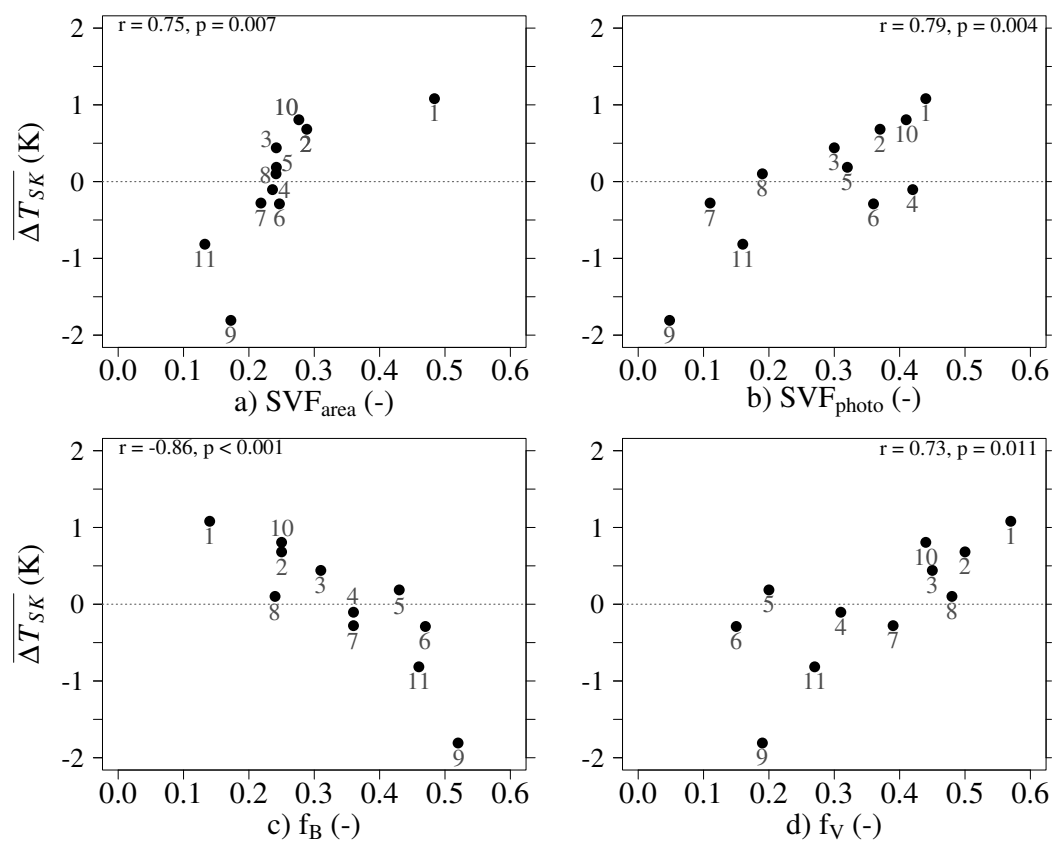

Figure 6. Daytime mean difference of each individual air temperature $(T)$ to the spatial mean daytime $T$ of all sites $\left(\Delta T_{S K}\right)$ at each measurement site within the Schillerkiez in relation to different urban morphometric parameters (a-d) on 24 June 2016. Correlation coefficients (r) and corresponding $p$-values are given for each parameter. $\mathrm{SVF}_{\text {area }}$ : areal sky view factor, $\mathrm{SVF}_{\text {photo }}$ : sky view factor calculated from fish-eye photos, $\mathrm{f}_{\mathrm{B}}$ : building surface fraction, $\mathrm{f}_{\mathrm{V}}$ : vegetation surface fraction. 


\subsection{Comparison with $T$ in Other LCZs}

During night-time, $\Delta T_{S K}$ at the site of the same LCZ class as the Schillerkiez, BAMB, is within the range of the absolute highest and lowest $\Delta T_{S K}$ within the Schillerkiez (except for one night) and most of the time positive (Figure 7). $T$ at SWIN (LCZ 5, open midrise) is similar to $T$ measured at the several sites in the Schillerkiez, whereby the temporal night-time range of $\Delta T_{S K}$ is higher than the spatio-temporal range in the Schillerkiez (light grey area, Figure 7). The three "rural" sites (KOEP, KANI and SCHN) and ROTH (LCZ 6, open low-rise) are distinctly colder than the Schillerkiez during night-time with a $\overline{\Delta T_{S K}}$ of up to $-4 \mathrm{~K}$ (KANI, LCZ B, scattered trees). KOEP and KANI also show markedly larger temporal night-time $\Delta T_{S K}$ ranges than the spatio-temporal range in the Schillerkiez. TEMP, the site on the neighbouring THF (LCZ D) is colder than the Schillerkiez but $\overline{\Delta T_{S K}}$ is about $1 \mathrm{~K}$ higher than SCHN (also LCZ D).

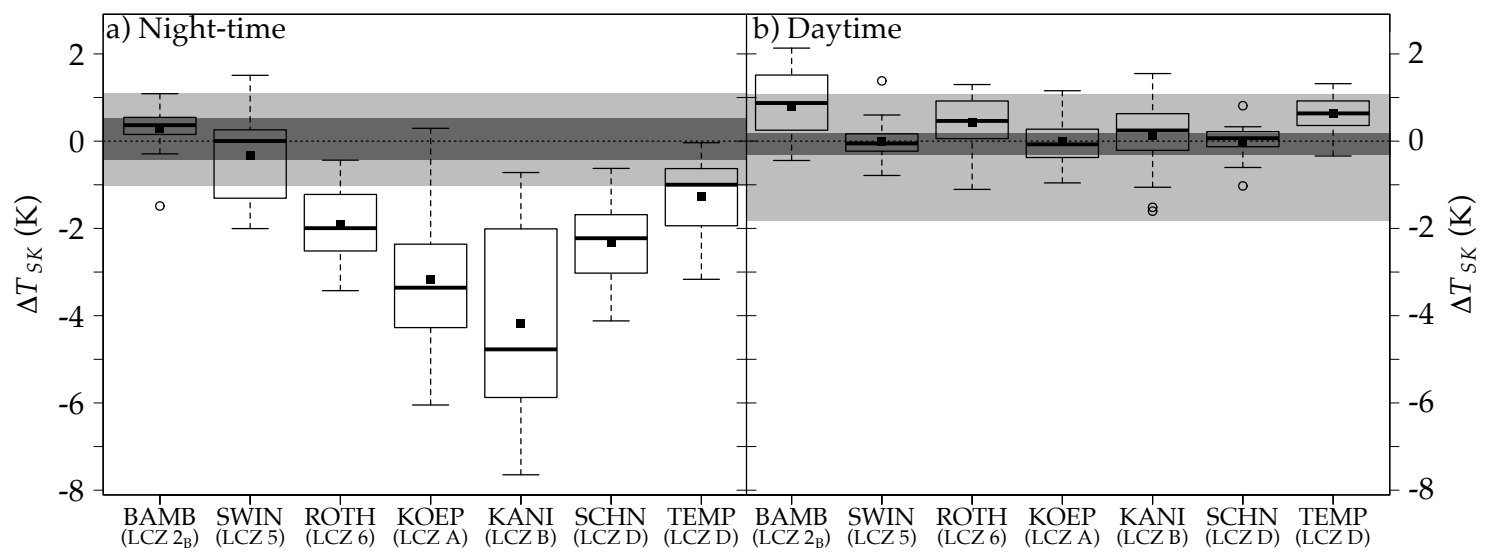

Figure 7. Air temperature $(T)$ differences $\left(\Delta T_{S K}\right)$ in various local climate zones (LCZs) in Berlin from the spatial mean $T$ across all sites within the study area Schillerkiez for 22 nights (left panel) and 22 days (right panel). The bold black line in each box shows the median, the black square the arithmetic temporal mean. Boxes include data points that are between the 1st and the 3rd quartile (interquartile range IQR). The whiskers show the remaining data points, maximum length is 1.5 times the IQR below the 1st and above the 3rd quartile. Data points outside of this are depicted as circles. Grey areas depict the range between the highest and lowest $\Delta T_{S K}$ among all sites within the Schillerkiez for all nights and days (light grey) and the range between the highest and lowest temporal mean $\left(\overline{\Delta T_{S K}}\right)$ among all sites across all 22 nights and days (dark grey).

At daytime, $\Delta T_{S K}$ at most sites is almost always within the range of the absolute highest and lowest $\Delta T_{S K}$ within the Schillerkiez. Only at the site of the same LCZ class (BAMB, sensor mounted to a balcony), $T$ is discernibly higher with a $\overline{\Delta T_{S K}}$ of $0.8 \mathrm{~K}$. The temporal daytime $\Delta T_{S K}$ ranges at the seven Berlin-wide sites tend to be smaller than the spatio-temporal range in the Schillerkiez (light grey area, Figure 7).

\section{Discussion}

\subsection{Air Temperature Variability within the LCZ and Influence of Micro-Scale Morphometric Parameters}

Within the study area, $\overline{\Delta T_{S K}}$ between $-0.4 \mathrm{~K}$ and $0.5 \mathrm{~K}$ during the night and $-0.3 \mathrm{~K}$ and $0.2 \mathrm{~K}$ during the day were detected. These deviations are within the range of deviations detected by Leconte et al. [7] for a LCZ 5 (between $-0.9 \mathrm{~K}$ and $0.5 \mathrm{~K}$ during night-time and $-0.6 \mathrm{~K}$ and $0.4 \mathrm{~K}$ at daytime). However, the deviations observed by Leconte et al. [7] are a bit higher than the results obtained in this study, corresponding to a higher structural heterogeneity in their LCZ. In accordance to their findings, the nocturnal $\overline{\Delta T_{S K}}$ range within the study area is larger than the one observed at daytime during all days. 
The observation of Leconte et al. [7] that nocturnal and diurnal cold- and hotspots do not necessarily coincide, could also be confirmed with this study. This is especially true for the single clear, calm and dry day when almost all sites that tend to be warmer than the spatial mean during the night are cooler during daytime and vice versa.

It should be noted that most of the detected $\Delta T_{S K}$ are within the sensors' twofold accuracy of $1 \mathrm{~K}$. However, systematic errors of the sensors were addressed by the calibration in the climate chamber and statistical errors are minimized by averaging one-minute sampled data over at least three hours.

\subsubsection{Night-Time Situation}

The analysis of night-time conditions shows a clear relation between the surface structure and $\overline{\Delta T_{S K}}$ (Figure 5), with $\mathrm{f}_{\mathrm{B}}$ showing the strongest correlation. This parameter is closely linked to the surface area of buildings that is available to absorb radiant energy during the day, store the heat and release it as sensible heat in the night [38,41]. The positive correlation confirms findings by Yan et al. [42] who also found a strong positive correlation $\left(R^{2}=0.64\right)$ for a radius of $50 \mathrm{~m}$ in Beijing, China.

Concerning vegetation, studies (reviewed by Bowler et al. [43]) suggest that tree canopies retain heat at night since they lower the SVF. Since $f_{V}$ in the study area is mainly made up by street trees, one could expect a positive correlation of $f_{V}$ with the nocturnal $T$. Albeit, the effect of street trees must be considered in regard to their surroundings, i.e., a built-up area. In fact, $\mathrm{f}_{\mathrm{V}}$ is negatively correlated with $\mathrm{f}_{\mathrm{B}}$ in the study area $(\mathrm{r}=-0.951, p<0.001)$. Therefore, the effect of vegetation cannot be assessed independently of the effect of buildings. However, our results suggest that the effect of buildings dominates over the effect of trees leading to the observed negative correlation of $\mathrm{f}_{\mathrm{V}}$ with nocturnal $T$.

Two different types of SVFs were investigated. SVF ${ }_{\text {photo }}$ gauges the openness of the site itself and hence the potential of radiation to enter or exit the site. SVFarea, on the contrary, is calculated over a larger area, depicting not only the openness of the spot itself but also of the area around it. At night-time, one would expect negative correlations of the SVFs and $T$, because the more open a site, the more longwave radiation can be emitted, enhancing the cooling at the site [44]. In outlines this nexus was found, though negative correlations were weak. Blankenstein and Kuttler [19] also found only weak negative correlations of night-time $T$ and $\mathrm{SVF}_{\text {photo, }}$, whereby such a correlation was strongest for built-up areas with vegetation. Yan et al. [21], however, could not find a significant correlation between $T$ and a $\mathrm{SVF}_{\text {area }}$ for a radius of $150 \mathrm{~m}$ during summer nights.

\subsubsection{Daytime Situation}

During the day, $T$ is mainly influenced by the incoming solar radiation and by thereby prompted turbulence and wind $[8,45]$. Due to this turbulence and wind, the air is continuously mixed and a correlation of daytime $\bar{T}$ during the measurement period to micro-scale urban fabric could not be observed. Solely on the single clear, calm and dry day $T$ patterns related to the micro-scale urban structure could form. Without wind, daytime $T$ is subject to the amount of solar radiation that can reach and heat up the direct surroundings of the measurement site [38,46]. Buildings reduce short wave radiation and hence the building fraction correlates negatively with $T$ during the clear, calm and dry day.

As described above, the SVFs show the openness of the site itself or the area around it for incoming solar radiation. As expected, the correlations are positive. The correlation between $S_{V F}$ photo and $\overline{\Delta T_{S K}}$ is slightly higher than the one between $S V F_{\text {area }}$ and $\overline{\Delta T_{S K}}$, whereby the second one is higher for a smaller radius of $20 \mathrm{~m}$ (see Appendix A). This corresponds to previous findings that the influence of man-made surface on $T$ is most relevant during the day when calculated for a small zone around the site [21]. It must be kept in mind that obtaining SVF-values from fish-eye-photographs is dependent on the placement of the camera. This limitation and the presented results thus clearly suggest that

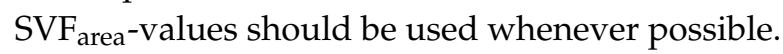


Regarding vegetation, several studies (reviewed by Bowler et al. [43]), indicate a negative correlation between daytime $T$ and $f_{\mathrm{V}}$ because of evapotranspiration and shading provided by trees. However, the observed correlation is positive during a clear, calm and dry day. This can be due to the already mentioned fact that $f_{V}$ correlates negatively with $f_{B}$. Within the study area, buildings provide more shading than trees, resulting in a lower $T$. It must be stressed, though, that the results for the $T$ regime during clear, calm and dry weather conditions were obtained during one single day. Further studies are needed to confirm this finding.

Also during daytime with radiation-dominated weather the neighbouring THF (LCZ D) could be warmer than the more shadowed Schillerkiez (LCZ 2B) and thus influence daytime $T$ within the Schillerkiez, leading to a possible negative correlation between the distance to the THF and $\triangle T_{T E M P}$. However, during the analyzed clear, calm and dry day, south wind was recorded during daytime. Therefor we assume a possible influence of the THF to be small. A more detailed analysis of this question could not be carried out due to the weather conditions during the measurement campaign (no radiation-dominated days with light east or west winds). Also, since it was not possible to integrate other influencing variables like the albedo or the anthropogenic heat flux into the analysis due to a lack of these data, it cannot be precluded that other variables might also have an effect on $T$.

\subsubsection{The Exceptional Site "Courtyard"}

Notable is site 9, the courtyard, that is a strong hotspot throughout the entire diurnal cycle for almost all days. This might be due to a special microclimate in the courtyard [37] which is small $\left(\sim 220 \mathrm{~m}^{2}\right)$, completely enclosed by buildings ( $20 \mathrm{~m}$ high) and thus isolated from the surroundings. Due to the low SVF at this site it can be assumed that the reduced radiative cooling leads to the different results compared to site 6, just outside the courtyard. Further, it can be suspected that the courtyard is cut off from the mixed atmosphere within the street canyons and the warmer air is "trapped" inside the courtyard. Only during the clear, calm and dry day, the expected cold spot forms in the courtyard. Lehnert et al. [14] similarly reported on such results from a measurement site within a closed courtyard, as these are also typical for the historical centre of Olomouc, Czech Republic. $T$ was typically lower than other sites during the day and higher at night during clear and calm days [14]. It must be stressed, though, that such locations are not suitable for measuring representative local-scale $T$ conditions [14]. However, courtyards represent an important part of the structural landscape in many European cities and hence contribute to the local climate conditions. Since these locations are also often the only option to securely install a measurement station, Lehnert et al. [14] stressed that it is of great importance that the selected courtyard is representative of the surrounding area in terms of surface cover fractions to obtain comparable results and to clearly indicate such a measurement site when reporting on the results. Considering this, the spatial mean of several measurement sites within a study area should be used to obtain representative results for a specific $\operatorname{LCZ}[7,9,15]$.

\subsection{Influence of the Neighbouring Urban Green Space}

Several studies that examined the cooling rates of inner-city parks during night-time periods detected a maximum of cold air production under calm and cloudless conditions [47-50]. Spronken-Smith and Oke [51] further remark that such a cooling is strongest in open parks, i.e., without or only few trees. At night, open parks like the THF as a LCZ D (low plants) exhibit higher cooling rates than adjacent built-up neighbourhoods due to the lack of heat storage capacity [38].

As depicted in Figure 4, during nights with eastern winds, the correlation between the distance to the THF and $T$ is-although significant-low. Nevertheless, $T$ is slightly rising with increasing distance to the THF. This could be explained by a correlation between the distance to the THF of sites with their $\mathrm{f}_{\mathrm{B}}(\mathrm{r}=0.73, p=0.01)$. The building blocks closer to the THF do not have any buildings in the courtyards, while the blocks further away do (Figure 1b). A potential influence of the THF can of course not be fully excluded during east-wind conditions, e.g., through a park breeze but the high correlation of $\overline{\Delta T_{S K}}$ with $\mathrm{f}_{\mathrm{B}}$ indicates a dominant influence of this parameter. 
During nights with west winds, when an influence of the green space can be anticipated considering the thermal source area of the sensors, the correlation between nocturnal $T$ and the distance of the respective site to the THF is strong and highly significant (Figure 4). Similar to the effect observed by Chow et al. [52] in Phoenix, USA, the cool air that forms on the THF could be transported by west winds into the Schillerkiez. This can also be seen in the fact that sites 7 and 9, located in a narrow N-S-oriented street and in a courtyard, seem to be less affected by the cooling influence of the THF. This could be due to a cut-off from the cool air flowing into the study area. Further studies, which could involve high-resolution large eddy simulations, could test this hypothesis and further try to delineate the influence of the building density and the distance to the green space.

The detected strength of the cooling influence during west winds-a $\Delta T$ of about $1.5 \mathrm{~K}$ between the sites closest to and furthest away from the border of the THF (a distance of $439 \mathrm{~m}$ ) - is similar to other studies. Doick et al. [50] detected a $\Delta T$ of 1 to $1.5 \mathrm{~K}$ over a distance of about $200 \mathrm{~m}$ in a street leading away from Hyde Park, London, UK. For Gothenburg, Sweden, Upmanis et al. [49] detected an influence of the park Slottskogen with a $\Delta T$ of about $2 \mathrm{~K}$ between the park border and about $1 \mathrm{~km}$ into the built-up neighbourhood. Spronken-Smith [53] and Upmanis et al. [49] suggest an influence of a green space as far into the adjacent built-up area as the green space's width. Since the THF is about two km wide in W-E direction, the extent of the cooling effect could not be assessed with the measurement set-up used.

\subsection{Comparison with $T$ in Other LCZs}

To assess the magnitude of the observed $T$ variability within the study area as well as the robustness of the LCZ scheme itself, a comparison to other locations in Berlin of different LCZ classes is presented (Figure 7). As suggested by other LCZ- and UHI-studies, nocturnal $\Delta T$ are more pronounced than at daytime [5,10], as during the day there is greater mixing of the surface layer and therefore little $\Delta T$ between the various sites [45]. Confirming this, $\Delta T_{S K}$ during the day at sites in other LCZ classes lie almost completely within the $\Delta T_{S K}$ range of the study area, even at the sites located in "natural" LCZs (KOEP, KANI and SCHN) that differ strongly from the Schillerkiez in terms of surface properties. Only at the site of the same LCZ class as the study area (BAMB), $\Delta T_{S K}$ differs more strongly at daytime, being in general higher than within the Schillerkiez. In addition to the three reasons given in the introduction (advection from surrounding areas, different surface characteristics within one LCZ class and micro-scale variability of surface characteristics) this higher daytime variability could be due to the differently set-up sensors. While the sensors in the Schillerkiez are fixed to tree trunks and thus shaded throughout the day, the sensor at BAMB is mounted to a balcony. It could hence be exposed to a higher $T$ if the adjacent building surface is exposed to direct solar radiation, leading to a higher surface temperature and thus also higher $T$ [54].

During the night, mean $\Delta T$ detected between LCZs $2_{\mathrm{B}}$ and 5 (Schillerkiez, BAMB and SWIN) and the rural sites (KOEP, KANI and SCHN) are similar to former findings of Stewart et al. [9] (between $2.2 \mathrm{~K}$ and $3.2 \mathrm{~K}$ ), Alexander and Mills [10] (between 3.2 $\mathrm{K}$ and $4.8 \mathrm{~K}$ ) and Leconte et al. [7] (between $2.4 \mathrm{~K}$ and $4.4 \mathrm{~K}$ ) for different European cities. The mean $\Delta T$ between the sites located in a LZC $2 \mathrm{~B}$ (Schillerkiez and BAMB) and in a LCZ 6 (ROTH) of about $2 \mathrm{~K}$ also confirm former findings [7-10]. The fact that $T$ in a LCZ 5 (SWIN) is similar to the Schillerkiez could partly be due to the nocturnal cooling influence of the neighbouring THF onto the investigated area, lowering $T$. The systematically negative $\Delta T_{S K}$ at TEMP indicate that, given the small distance between TEMP and Schillerkiez, $\Delta T$ can be attributed to local-scale surface properties and thus the LCZ concept to be meaningful.

The intra-LCZ class comparison for LCZ class 2 2 shows a good congruence of the night-time $T$ measured in the two LCZs of the same class (Schillerkiez and BAMB). The slightly higher $\overline{\Delta T_{S K}}$ at $\mathrm{BAMB}$ still lies within the range between highest and lowest $\overline{\Delta T_{S K}}$ from the Schillerkiez (dark grey area, Figure 7). Even though some sites do not follow Lelovics et al.'s [55] suggestion of a minimum distance of $250 \mathrm{~m}$ from the border of a LCZ to a site, the observed intra-LCZ T variability within one neighborhood is similar to intra-LCZ class variability. It must be stressed that the obtained results 
are limited to LCZ class $2_{B}$, further studies in other LCZ classes and other cities are needed. Another intra-LCZ class comparison can be made between SCHN and TEMP (LCZ D). Here, the inner-city green-space THF (TEMP) is warmer than the airport located at the outskirts of the city (SCHN) at night-time. This indicates a mesoscale influence of the surrounding city on $T$ at TEMP (cf. [11]). This finding belongs to the question of intra-LCZ class $T$ variability across large distances which goes beyond the scope of this study and could be part of future research.

\section{Conclusions}

The variety of surface properties in urban areas lead to a unique air temperature pattern, even within a LCZ that appears to be relatively homogeneous. Using a dense network of stationary measurements during summer in one single LCZ $2_{\mathrm{B}}$ (compact midrise with scattered trees), this sub-scale $T$ variability was studied and the underlying causes were investigated. The temporal mean sub-scale $\Delta T$ during night-time (daytime) is $1 \mathrm{~K}(0.5 \mathrm{~K})$ between the warmest and the coldest spot. During a clear, calm and dry day this difference reaches up to $3 \mathrm{~K}$ during daytime. The observed night- and daytime $T$ variability can best be explained by the building surface fraction within a $50 \mathrm{~m}$ radius around each site. Spatial mean SVFs calculated for the same area are correlated more strongly to night-time $T$ variability compared to SVFs based on fish-eye photographs. Instead, the latter values showed higher correlations during daytime for a clear, calm and dry day.

The influence of an adjacent, very different LCZ D (low plants) onto the nocturnal $T$ is pronounced when the wind is coming from this area. Thus, for future measurements, single sites that shall represent certain LCZs should be located as far away as possible from adjacent LCZs of different classes to avoid possible influences. Further, influences of micro-scale characteristics should also be minimized when selecting single locations for LCZ measurements. Nonetheless, so far rarely sampled courtyards with a unique micro climate represent large parts of dense urban LCZs in central Europe. Thus, a spatial mean over numerous $T$ observations would be best, including such locations to obtain representative local-scale results. To even better reflect the reality of geographical space in terms of thermal conditions, it would be beneficial to provide a $T$ range for specific LCZs obtained from multiple observational sites.

The comparison between night-time $T$ in different LCZs in Berlin shows large differences between dissimilar classes and similarities for the same LCZ class as the study area. In addition, the observed $T$ range within one LCZ is smaller than most inter-LCZ T differences. Hence, despite the micro-scale variability within one LCZ, the general validity of the LCZ scheme could be confirmed. However, structurally similar classes such as LCZ $2_{\mathrm{B}}$ and 5 show similar $T$ conditions, making a clear differentiation difficult; even more so when measurements are obtained in LCZ subclasses.

The findings obtained from this study should be extended to other LCZ classes and other urban and climatic regions by further studies. Other parameters that might explain micro-scale $T$ variability could also be incorporated. Additionally, the focus might be set on other meteorological variables such as humidity, to find out whether the LCZ scheme is also applicable for those variables.

Supplementary Materials: The following are available online at www.mdpi.com/2225-1154/6/1/5/s1.

Acknowledgments: This research resulted from a masters' project named "Urban Climate" and we are grateful to all participants for supporting the measurement campaign. We acknowledge support by the German Research Foundation and the Open Access Publication Funds of Technische Universität Berlin. The study was part of the research project 'Heat waves in Berlin, Germany-urban climate modifications' funded by the Deutsche Forschungsgemeinschaft (DFG) under grant SCHE 750/15-1 (D.F.) and the research project 'Three-dimensional observation of atmospheric processes in cities (3DO), funded by the German Federal Ministry of Education and Research under grant FKZ 01LP1602 (A.H.). D.F. and A.H. were also partly funded by the Technische Universität Berlin. We thank the Straßen- und Grünflächenamt (road and green areas department) of the district Berlin-Neukölln and those who allowed measurements in their courtyard for supporting our study.

Author Contributions: All authors conceived, designed and performed the measurement campaign; Justus A. Quanz, Susanne Ulrich and Jonas Eimermacher analysed the data; all authors interpreted and discussed the results and wrote the paper, especially Justus A. Quanz and Susanne Ulrich. 
Conflicts of Interest: The authors declare no conflict of interest. The founding sponsors had no role in the design of the study; in the collection, analyses, or interpretation of data; in the writing of the manuscript and in the decision to publish the results.

\section{Appendix}

To identify the radius for which the urban surface properties have the strongest correlation, the corresponding parameters were calculated for radii from $10 \mathrm{~m}$ to $100 \mathrm{~m}$ around each site in steps of $10 \mathrm{~m}$. For night-time, the correlation is strongest for a $70 \mathrm{~m}$ radius (Figure A1a, grey lines). When using only nights having east wind, the strongest correlation can be found for a $50 \mathrm{~m}$ radius and decreases with increasing radii (Figure A1a, black lines).

In contrast, during daytime no significant correlation between $\overline{\Delta T_{S K}}$ and any morphometric parameter can be found (grey lines in Figure A1b). This is different when using only data of the dry, calm and cloud-free day (24 June 2016, black lines in Figure A1b). The smallest radius for which all metric parameters show a significant correlation is at $50 \mathrm{~m}$.
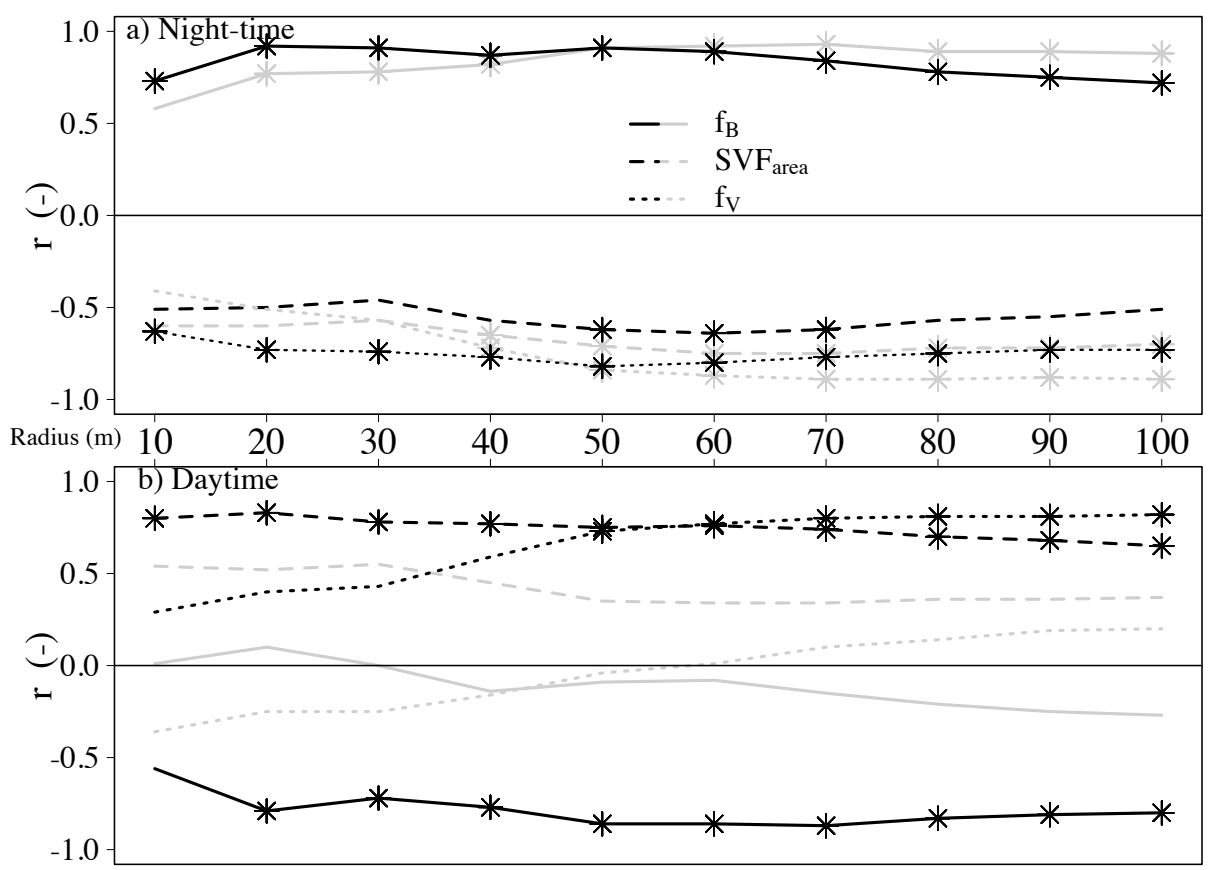

Figure A1. (a) Correlation coefficient $r$ between night-time mean air temperature within the study area and different morphometric parameters over different radii. Black lines: nights with east wind; grey lines: all nights. (b) Same as (a) but for daytime. Black lines: clear, calm, dry day (24 June 2016); grey lines: all days. Stars indicate significant correlations $(p<0.05)$.

\section{References}

1. Orlanski, L. A rational subdivision of scale for atmospheric processes. Bull. Am. Meteorol. Soc. 1975, 56, 527-530.

2. Oke, T.R. The distinction between canopy and boundary-layer urban heat islands. Atmosphere 1976, 14, 268-277. [CrossRef]

3. Oke, T. Methods in urban climatology. Appl. Climatol. 1984, 14, 19-29.

4. Oke, T. The micrometeorology of the urban forest. Philos. Trans. R. Soc. Lond. Ser. B Biol. Sci. 1989, 324, 335-349. [CrossRef]

5. Stewart, I.D.; Oke, T.R. Local Climate Zones for Urban Temperature Studies. Bull. Am. Meteorol. Soc. 2012, 93, 1879-1900. [CrossRef] 
6. Bokwa, A.; Hajto, M.J.; Walawender, J.P.; Szymanowski, M. Influence of diversified relief on the urban heat island in the city of Kraków, Poland. Theor. Appl. Climatol. 2015, 122, 365-382. [CrossRef]

7. Leconte, F.; Bouyer, J.; Claverie, R.; Pétrissans, M. Using Local Climate Zone scheme for UHI assessment: Evaluation of the method using mobile measurements. Build. Environ. 2015, 83, 39-49. [CrossRef]

8. Skarbit, N.; Stewart, I.D.; Unger, J.; Gál, T. Employing an urban meteorological network to monitor air temperature conditions in the 'local climate zones' of Szeged, Hungary. Int. J. Climatol. 2017, 37, 582-596. [CrossRef]

9. Stewart, I.D.; Oke, T.; Krayenhoff, E.S. Evaluation of the 'local climate zone' scheme using temperature observations and model simulations. Int. J. Climatol. 2014, 34, 1062-1080. [CrossRef]

10. Alexander, J.P.; Mills, G. Local Climate Classification and Dublin's Urban Heat Island. Atmosphere 2014, 5, 755-774. [CrossRef]

11. Fenner, D.; Meier, F.; Scherer, D.; Polze, A. Spatial and temporal air temperature variability in Berlin, Germany, during the years 2001-2010. Urban Clim. 2014, 10, 308-331. [CrossRef]

12. Emmanuel, R.; Krüger, E. Urban heat island and its impact on climate change resilience in a shrinking city: The case of Glasgow, UK. Build. Environ. 2012, 53, 137-149. [CrossRef]

13. Arnds, D.; Böhner, J.; Bechtel, B. Spatio-temporal variance and meteorological drivers of the urban heat island in a European city. Theor. Appl. Climatol. 2017, 128, 43-61. [CrossRef]

14. Lehnert, M.; Geletič, J.; Husák, J.; Vysoudil, M. Urban field classification by "local climate zones" in a medium-sized Central European city: The case of Olomouc (Czech Republic). Theor. Appl. Climatol. 2015, 122, 531-541. [CrossRef]

15. Fenner, D.; Meier, F.; Bechtel, B.; Otto, M.; Scherer, D. Intra and inter "local climate zone" variability of air temperature as observed by crowdsourced citizen weather stations in Berlin, Germany. Meteorol. Z. 2017, 26, 525-547. [CrossRef]

16. Houet, T.; Pigeon, G. Mapping urban climate zones and quantifying climate behaviors-An application on Toulouse urban area (France). Environ. Pollut. 2011, 159, 2180-2192. [CrossRef] [PubMed]

17. Bassett, R.; Cai, X.; Chapman, L.; Heaviside, C.; Thornes, J.E.; Muller, C.L.; Young, D.T.; Warren, E.L. Observations of urban heat island advection from a high-density monitoring network. Q. J. R. Meteorol. Soc. 2016, 142, 2434-2441. [CrossRef]

18. Andreou, E.; Axarli, K. Investigation of urban canyon microclimate in traditional and contemporary environment. Experimental investigation and parametric analysis. Renew. Energy 2012, 43, 354-363. [CrossRef]

19. Blankenstein, S.; Kuttler, W. Impact of street geometry on downward longwave radiation and air temperature in an urban environment. Meteorol. Z. 2004, 13, 373-379. [CrossRef]

20. Eliasson, I. Urban nocturnal temperatures, street geometry and land use. Atmos. Environ. 1996, 30, 379-392. [CrossRef]

21. Yan, H.; Fan, S.; Guo, C.; Wu, F.; Zhang, N.; Dong, L. Assessing the effects of landscape design parameters on intra-urban air temperature variability: The case of Beijing, China. Build. Environ. 2014, 76, 44-53. [CrossRef]

22. Nadeau, D.F.; Brutsaert, W.; Parlange, M.B.; Bou-Zeid, E.; Barrenetxea, G.; Couach, O.; Boldi, M.-O.; Selker, J.S.; Vetterli, M. Estimation of urban sensible heat flux using a dense wireless network of observations. Environ. Fluid Mech. 2009, 9, 635-653. [CrossRef]

23. Thepvilojanapong, N.; Ono, T.; Tobe, Y. A Deployment of Fine-Grained Sensor Network and Empirical Analysis of Urban Temperature. Sensors 2010, 10, 2217-2241. [CrossRef] [PubMed]

24. Hawkins, T.W.; Brazel, A.J.; Stefanov, W.L.; Bigler, W.; Saffell, E.M. The Role of Rural Variability in Urban Heat Island Determination for Phoenix, Arizona. J. Appl. Meteorol. 2004, 43, 476-486. [CrossRef]

25. Lengfeld, K.; Ament, F. Observing Local-Scale Variability of Near-Surface Temperature and Humidity Using a Wireless Sensor Network. J. Appl. Meteorol. Climatol. 2012, 51, 30-41. [CrossRef]

26. Statistical Office for Berlin-Brandenburg. Statistischer Bericht. A I 5-hj 1/16: Einwohnerinnen und Einwohner im Land Berlin am 30. Juni 2016. Available online: https:/ /www.statistik-berlin-brandenburg. de/publikationen/stat_berichte/2016/SB_A01-05-00_2016h01_BE.pdf (accessed on 30 November 2017).

27. Berlin Senate Department for Urban Development and the Environment, Urban and Environmental Information System. Environmental Atlas: Terrain Elevations. Available online: http://fbinter.stadtberlin.de/fb/index.jsp?Szenario=fb_en (accessed on 30 November 2017). 
28. Kottek, M.; Grieser, J.; Beck, C.; Rudolf, B.; Rubel, F. World map of the Köppen-Geiger climate classification updated. Meteorol. Z. 2006, 15, 259-263. [CrossRef]

29. DWD Climate Data Center (CDC). Historical Daily Station Observations (Air Temperature, Pressure, Precipitation, Sunshine Duration, etc.) for Germany, version v005; DWD: Offenbach, Germany, 2017.

30. Berlin Senate Department for Urban Development and the Environment Urban and Environmental Information System. Environmental Atlas: Building and Vegetation Heights. Available online: http:/ / www.stadtentwicklung.berlin.de/umwelt/umweltatlas/ei610.htm (accessed on 30 November 2017).

31. Lindberg, F.; Holmer, B.; Thorsson, S. SOLWEIG 1.0-Modelling spatial variations of 3D radiant fluxes and mean radiant temperature in complex urban settings. Int. J. Biometeorol. 2008, 52, 697-713. [CrossRef] [PubMed]

32. Konarska, J.; Lindberg, F.; Larsson, A.; Thorsson, S.; Holmer, B. Transmissivity of solar radiation through crowns of single urban trees-application for outdoor thermal comfort modelling. Theor. Appl. Climatol. 2014, 117, 363-376. [CrossRef]

33. Meier, F.; Fenner, D.; Grassmann, T.; Otto, M.; Scherer, D. Crowdsourcing air temperature from citizen weather stations for urban climate research. Urban Clim. 2017, 19, 170-191. [CrossRef]

34. Kaspar, F.; Müller-Westermeier, G.; Penda, E.; Mächel, H.; Zimmermann, K.; Kaiser-Weiss, A.; Deutschländer, T. Monitoring of climate change in Germany-Data, products and services of Germany's National Climate Data Centre. Adv. Sci. Res. 2013, 10, 99-106. [CrossRef]

35. Berlin Senate Department for Urban Development and the Environment Urban and Environmental Information System. Environmental Atlas: Land Use. Available online: http:/ / www.stadtentwicklung. berlin.de/umwelt/umweltatlas/edua_index.shtml (accessed on 30 November 2017).

36. Google Earth DWD Schönefeld (SCHN). Available online: https://www.google.com/earth/ (accessed on 30 November 2017).

37. Oke, T.R. Initial Guidance to Obtain Representative Meteorological Observations at Urban Sites; World Meteorological Organization: Geneva, Switzerland, 2006; p. 47.

38. Oke, T. The energetic basis of the Urban heat-island. Q. J. R. Meteorol. Soc. 1982, 108, 1-24. [CrossRef]

39. Erell, E.; Williamson, T. Intra-urban differences in canopy layer air temperature at a mid-latitude city. Int. J. Climatol. 2007, 27, 1243-1255. [CrossRef]

40. Middel, A.; Häb, K.; Brazel, A.J.; Martin, C.A.; Guhathakurta, S. Impact of urban form and design on mid-afternoon microclimate in Phoenix Local Climate Zones. Landsc. Urban Plan. 2014, 122, 16-28. [CrossRef]

41. Mirzaei, P.A.; Haghighat, F. Approaches to study Urban Heat Island-Abilities and limitations. Build. Environ. 2010, 45, 2192-2201. [CrossRef]

42. Yan, H.; Fan, S.; Guo, C.; Hu, J.; Dong, L. Quantifying the Impact of Land Cover Composition on Intra-Urban Air Temperature Variations at a Mid-Latitude City. PLoS ONE 2014, 9, e102124. [CrossRef] [PubMed]

43. Bowler, D.E.; Buyung-Ali, L.; Knight, T.M.; Pullin, A.S. Urban greening to cool towns and cities: A systematic review of the empirical evidence. Landsc. Urban Plan. 2010, 97, 147-155. [CrossRef]

44. Giridharan, R.; Lau, S.S.Y.; Ganesan, S.; Givoni, B. Urban design factors influencing heat island intensity in high-rise high-density environments of Hong Kong. Build. Environ. 2007, 42, 3669-3684. [CrossRef]

45. Oke, T.R. Boundary Layer Climates, 2nd ed.; Routledge, Taylor and Francis Group: London, UK; New York, NY, USA, 1987; ISBN 0-416-04422-0.

46. Christen, A.; Vogt, R. Energy and radiation balance of a central European city. Int. J. Climatol. 2004, 24, 1395-1421. [CrossRef]

47. Spronken-Smith, R.A.; Oke, T.R. The thermal regime of urban parks in two cities with different summer climates. Int. J. Remote Sens. 1998, 19, 2085-2104. [CrossRef]

48. Morris, C.J.G.; Simmonds, I.; Plummer, N. Quantification of the Influences of Wind and Cloud on the Nocturnal Urban Heat Island of a Large City. J. Appl. Meteorol. 2001, 40, 169-182. [CrossRef]

49. Upmanis, H.; Eliasson, I.; Lindqvist, S. The influence of green areas on nocturnal temperatures in a high latitude city (Göteborg, Sweden). Int. J. Climatol. 1998, 18, 681-700. [CrossRef]

50. Doick, K.J.; Peace, A.; Hutchings, T.R. The role of one large greenspace in mitigating London's nocturnal urban heat island. Sci. Total Environ. 2014, 493, 662-671. [CrossRef] [PubMed]

51. Spronken-Smith, R.A.; Oke, T.R. Scale Modelling of Nocturnal Cooling in Urban Parks. Bound.-Layer Meteorol. 1999, 93, 287-312. [CrossRef] 
52. Chow, W.T.L.; Pope, R.L.; Martin, C.A.; Brazel, A.J. Observing and modeling the nocturnal park cool island of an arid city: Horizontal and vertical impacts. Theor. Appl. Climatol. 2011, 103, 197-211. [CrossRef]

53. Spronken-Smith, R.A. Energetics and Cooling in Urban Parks. Ph.D. Thesis, University of British Columbia, Vancouver, BC, Canada, 1994.

54. Nakamura, Y.; Oke, T.R. Wind, temperature and stability conditions in an east-west oriented urban canyon. Atmos. Environ. 1988, 22, 2691-2700. [CrossRef]

55. Lelovics, E.; Unger, J.; Gál, T.; Gál, C. Design of an urban monitoring network based on Local Climate Zone mapping and temperature pattern modelling. Clim. Res. 2014, 60, 51-62. [CrossRef]

(C) 2018 by the authors. Licensee MDPI, Basel, Switzerland. This article is an open access article distributed under the terms and conditions of the Creative Commons Attribution (CC BY) license (http://creativecommons.org/licenses/by/4.0/). 